\title{
PERANCANGAN BOOTH PAMERAN KOMUNITAS WARP SEBAGAI HASIL PENGABDIAN MASYARAKAT
}

\author{
Thetania Mega Risadewi ${ }^{1)}$, Maria Fransisca Listiarini Cahyadi ${ }^{21}$ \\ ${ }^{1}$ Seni dan Desain, Universitas Kristen Petra, Surabaya \\ email: thetania_mega@yahoo.com \\ ${ }^{2}$ Seni dan Desain, Universitas Kristen Petra, Surabaya \\ email: mariafransiscalc1998@gmail.com
}

\begin{abstract}
There are a lot of creative communities in Surabaya, one of them is Waste Recycling Project (WARP). WARP is a community which focused on disposing plastic wastes into creative products. WARP Community provides a solution for environment problems and also supports Surabaya to become a Creative City in design field which can attracts tourists. The problem that needs to be solved is WARP Community's needs space especially for an exhibition. The purpose of this design is to support community's activities. Moreover, it could expand WARP's potential in Surabaya through the design's appliance. The method used for this design is Design Thinking, which covers understand, ideate, prototype, and test. The results of this community service is creative product in shape of exhibition booth with "Hexatica" as the concept.
\end{abstract}

Keywords: komunitas, design thinking, booth.

\section{PENDAHULUAN}

Di Indonesia, kerusakan lingkungan sudah dinilai mengkhawatirkan, terutama permasalahan sampah plastik. Sampah plastik dapat mencemari lingkungan seperti banjir dan bahkan merusak ekosistem. Permasalahan ini perlu diatasi untuk mencegah dampak yang lebih besar. Oleh karena itu, program 3R (reuse, recycle, reduce) dapat menjadi salah satu solusi. Dampak dari itu, komunitas Waste Recycling Project (WARP) menjadikan permasalahan sampah sebagai masalah krusial yang perlu dihadapi. Komunitas ini bergerak di bidang pengolahan limbah plastik menjadi barang bernilai. Melalui metode design thinking, mahasiswa dapat berinteraksi secara langsung untuk terlibat dalam aktivitas komunitas WARP. Selain itu, mahasiswa juga dapat mengetahui kebutuhan dan keinginan dari komunitas tersebut. Bedasarkan fenomena di atas dapat dirumuskan bahwa metode design thinking diperlukan untuk perancangan exhibition booth komunitas WARP.

\section{KAJIAN LITERATUR}

\section{Definisi Komunitas}

Menurut Stewart E Perry, ada dua makna komunitas; pertama, komunitas sebagai kategori yang mengacu pada orang yang saling berhubungan berdasarkan nilai-nilai dan kepentingan bersama yang khusus. Kedua, menunjuk pada satu kategori manusia yang berhubungan satu sama lain karena didasarkan pada lokalitas tertentu yang sama, yang karena kesamaan lokalitas itu secara tak langsung membuat mereka mengacu pada kepentingandan nilai-nilai yang sama (Primadona, 2007).

\section{Definisi Design Thinking}

Design Thinking adalah metode dalam melakukan proses desain. Metode ini berfokus pada pengguna yang dapat menyelesaikan masalah. Design Thinking memiliki beberapa elemen penting yaitu:

1. People centered Metode yang berpusat pada kebutuhan dan keinginan pengguna.

\section{Highly creative}

Metode yang menggunakan kreativitas sebebasnya, tidak perlu aturan yang terlalu kaki dan baku.

\section{Hands on}

Proses desain yang memerlukan percobaan langsung oleh tim desain, bukan hanya pembuatan teori atau sebuah gambaran di kertas.

4. Iterative

Proses desain dengan mengulang tahapan-tahapan untuk melakukan improvisasi dan menghasilkan sebuah produk atau aplikasi yang baik (Moote, 2013). 


\section{Definisi Booth}

Menurut Cambridge Dictionary, booth adalah ruang kecil seperti box yang bisa dimasuki orang; tenda kecil. Apabila dihubungkan dengan kegiatan pameran, booth bisa diartikan sebagai stan yang digunakan untuk mempromosikan produk atau jasa suatu brand.

\section{METODE PENELITIAN}

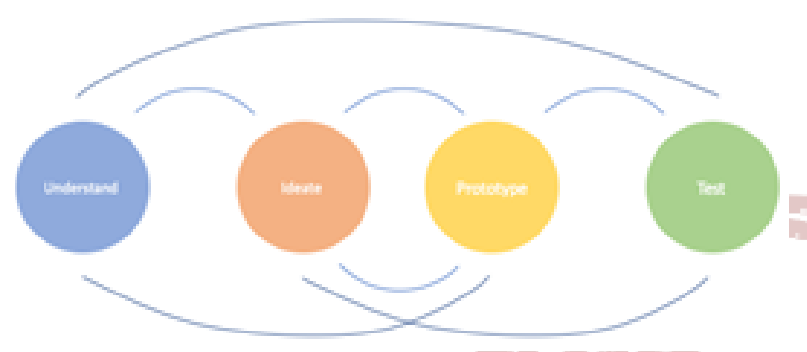

Gambar 1. Metode Design Thinking (Sumber: Risadewi, 2019)

Objek perancangan ini adalah kegiatan pameran komunitas WARP menggunakan metode design thinking, yaitu:

a. Understand, melakukan observasi dan dokumentasi komunitas WARP yang berada di kota Surabaya.

b. Ideate, membuat konsep desain yang sesuai dengan tujuan dan masalah.

c. Prototype, perancangan yang sudah sesuai divisualisasikan ke dalam render $3 \mathrm{D}$ dan gambar kerja.

d. Test, hasil perancangan dipresentasi-kan kepada pihak komunitas WARP untuk mendapat feedback.

\section{HASIL DAN PEMBAHASAN}

a. Understand, tahap pertama yang dilakukan dengan wawancara untuk mendapatkan latar belakang, visi misi, dan tujuan dari komunitas WARP. Komunitas WARP merupakan komunitas yang peduli terhadap lingkungan terutama sampah plastik. Setelah berhasil menciptakan sebuah produk kreatif dari sampah plastik, komunitas WARP mengadakan penyuluhan kepada masyarakat dengan dua metode yaitu workshop dan pameran.

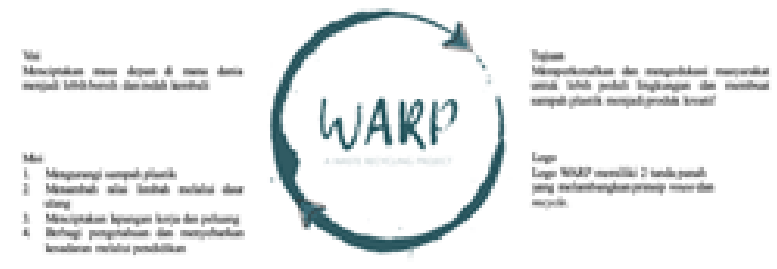

Gambar 2. Hasil Wawancara

(Sumber: Risadewi, 2019)

Selama mengikuti workshop dan pameran yang dilakukan komunitas WARP, dapat disimpulkan permasalahan yang dihadapi yaitu kebutuhan booth untuk meletakkan produk hasil WARP saat pameran maupun workshop. Hal ini didapat dari hasil pengamatan dimana produk hanya sekadar diletakkan pada tempat yang disediakan.

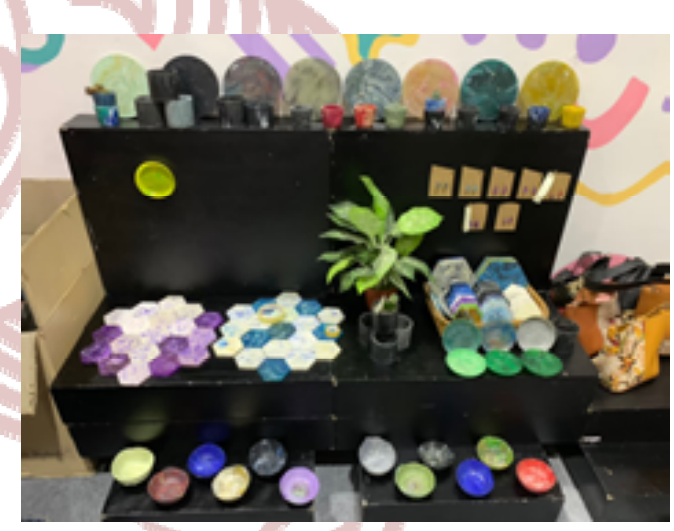

Gambar 2. Suasana Pameran (Sumber: Risadewi, 2019)

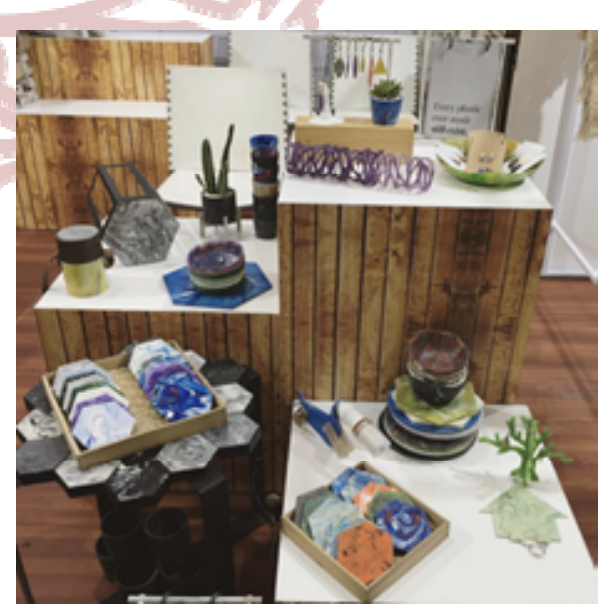

Gambar 3. Suasana Pameran (sumber: instagram/warp.sby, 2019)

b. Ideate, dalam proses membuat konsep desain penulis konsultasi dengan dosen pembimbing maupun pihak dari komunitas WARP untuk mendapatkan hasil desain yang maksimal. 


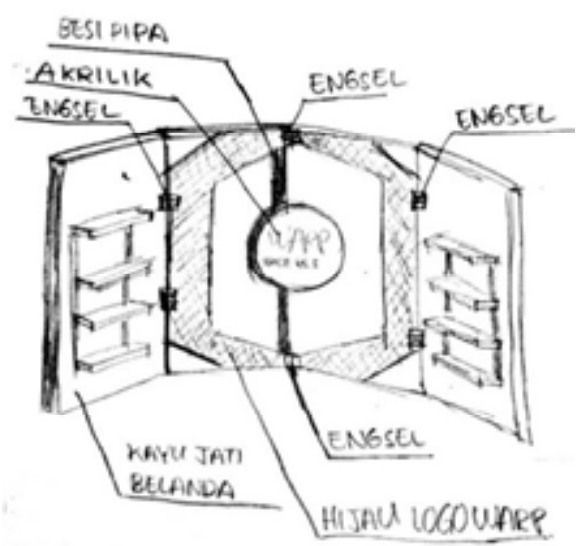

Gambar 4. Sketsa Desain dan Material

(Sumber: Risadewi, 2019)

c. Konsep desain dari booth ini adalah Hexatica yang berasal dari bentuk heksagon dan juga diimplementasikan dalam desain booth. Hexagon merupakan sebuah bidang segi enam yang menjadi simbol persatuan dan kekokohan. Bentuk ini dipilih karena hasil produk pertama komunitas WARP adalah hexagon. Selain itu, posisi sisinya yang simetris sehingga booth tetap terlihat menarik meski dilihat dari segala arah. Warna hijau diletakkan pada bentuk hexagon agar menjadi focal point dari booth sehingga tidak terkesan monoton. Bentuk dan warna hexagon ini juga merupakan hasil implementasi dari makna logo WARP yang melambangkan recycle dan reuse. Fungsi Hexatica booth ini adalah sebagai stan untuk showcase aksesoris dan pernak-pernik.

d. Prototype, perancangan yang sudah sesuai divisualisasikan ke dalam render 3D dan gambar kerja menggunakan aplikasi software komputer untuk media presentasi kepada komunitas.

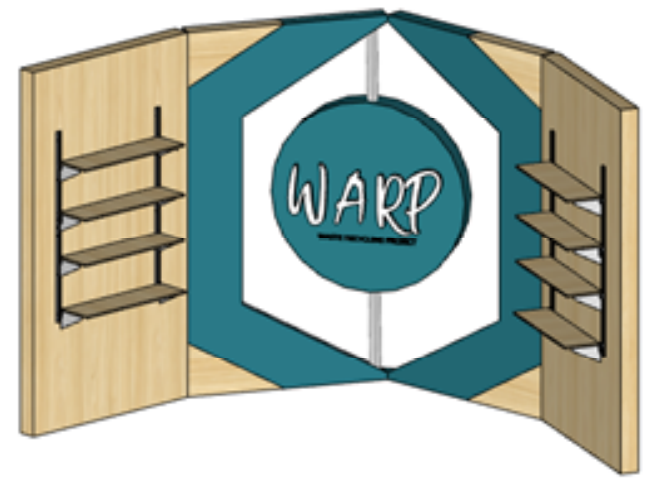

Gambar 5. hasil render (Sumber: Risadewi, 2019)

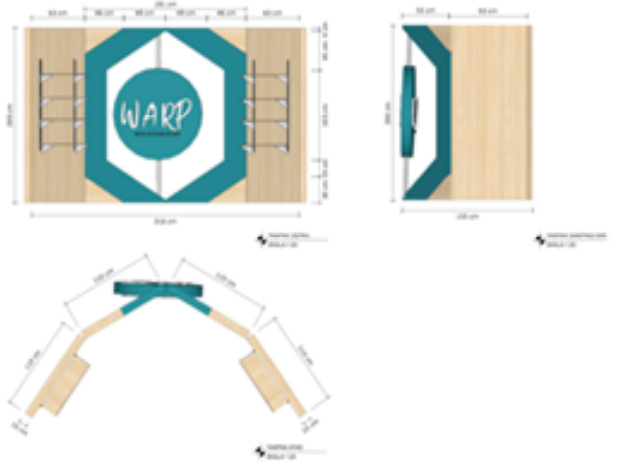

Gambar 6. Gambar Kerja (Sumber: Risadewi, 2019)

Gambar kerja diperlukan untuk menunjukkan dimensi dari perancangan booth. Selain itu, gambar kerja berfungsi untuk media komunikasi dengan tukang jika perancangan booth ini akan direalisasikan 1:1.

e. Test, hasil perancangan ini merupakan gagasan perancangan desain. Selain menunjukkan gambar $3 \mathrm{D}$ render, maket 1:10 digunakan untuk media presentasi dengan pihak komunitas WARP. Hal ini dilakukan untuk memudahkan penjelasan terkait sistem konstruksi dan manfaat dari perancangan booth ini.

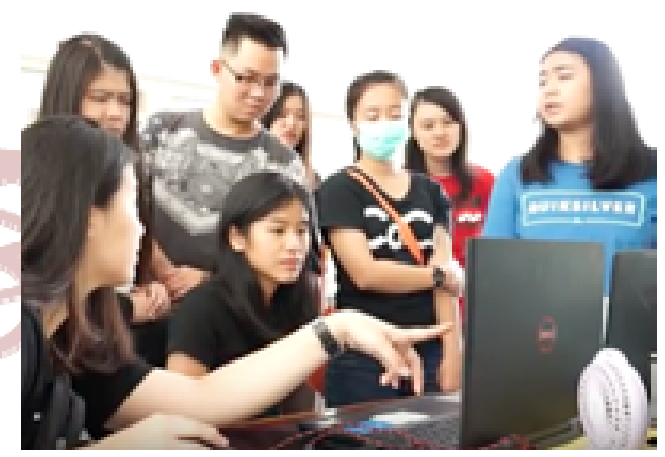

Gambar 7. Suasana Presentasi

(Sumber: Risadewi, 2019)

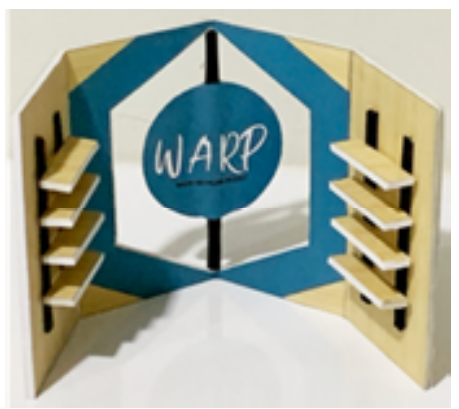

Gambar 8. Maket 1:10

(Sumber: Risadewi, 2019) 


\section{KESIMPULAN}

Permasalahan sampah plastik yang menumpuk harus diatasi, salah satunya dengan pendekatan ilmu desain. IImu desain dapat membantu keberadaan komunitas WARP dalam mengurangi sampah plastik menjadi produk kreatif. Implementasi konsep "hexatica" pada booth WARP menjawab kebutuhan display yang efektif dan efisien saat pameran dan worskhop. Desain dan konstruksi booth dibuat sederhana agar dapat disimpan dan dibawa dengan mudah. Perancangan booth untuk komunitas WARP, diharapkan dapat memberi dukungan dan fasilitas untuk komunitas dalam melakukan aktivitas sesuai dengan tujuannya. Selain itu, komunitas WARP juga dapat meningkatkan eksistensinya kepada masyarakat serta meningkatkan kesadaran masyarakat akan sampah plastik.

\section{UCAPAN TERIMA KASIH}

Puji dan syukur kepada Tuhan Yesus Kristus atas berkat rahmatNya penulis dapat menyelesaikan artikel ilmiah. Pada kesempatan ini penulis mengucapkan terima kasih kepada pihak-pihak yang telah membantu dalam menyelesaikan perancangan dan artikel ilmiah, sebagai berikut:
1. Dr. Laksmi K. Wardani, S.Sn, M.Ds selaku kepala studio dan dosen mata kuliah seminar yang telah membimbing dan memberi arahan kepada penulis dalam menulis artikel ilmiah.

2. Ronald H.I Sitindjak, S. Sn, M.Sn selaku tutor yang telah banyak meluangkan waktu, tenaga, dan pikiran dalam memberikan pengarahan dalam perancangan booth pameran WARP.

3. Komunitas Waste Recycle Project (WARP) selaku objek perancangan booth pameran.

\section{DAFTAR PUSTAKA}

Cambridge Dictionary: Booth (Diakses tanggal: 24 Oktober 2019)

Moote, Idris, Design Thinking for Strategic Innovation, New Jersey: John Wiley \& Sons, Inc. (2013)

Primadona, N. (2007). Persepsi masyarakat Siwalankerto terhadap program pengabdian masyarakat yang dijalankan melalui program service learning desain rumah sederhana. Surabaya: Universitas Kristen Petra-Fakultas IImu Komunikasi. 